ORIGINAL ARTICLE

\title{
Pattern of Neuropsychiatric Illnesses in Geriatric Population: An Outpatient Study Report
}

\author{
Aich TK ${ }^{1}$, Shah S², Subedi S ${ }^{3}$ \\ 1.Associate Professor and Head, Department of Psychiatry, BRD Medical College, Gorakhpur, \\ India 2. Assistant Professor, Department of Psychiatry, UCMS, Bhairahawa, Nepal 3. Associate \\ Professor, Department of Psychiatry, UCMS, Bhairahawa, Nepal.
}

E-mail *Corresponding author: tapas_dr@yahoo.co.in

\begin{abstract}
Introduction: Few studies are available till date on the pattern of neuro-psychiatric illnesses in geriatric population in Nepal.

Objective: The study was aimed to know the demographic and clinical profiles of geriatric outpatients in our neuropsychiatry OPD.

Method: This study was conducted at the Department of Psychiatry, Universal College of Medical SciencesTeaching Hospital (UCMS-TH), Bhairahawa, Nepal. We screened through our 'OPD case registrar', which maintains few demographic and clinical data of all the new and old cases registered daily in the OPD. Sociodemographic and clinical data of all the patients in the age of 60 years and above were noted in a data sheet specially designed for the present study. This is a retrospective study by chart review. Descriptive analysis of these data were undertaken by using simple frequency distribution.
\end{abstract}

Result: During the one year study period total number of new patients registered were 3711. Two-hundred and fifty-seven (6.9\%) among them were in the geriatric age group ( $\geq 60$ years age). Psychoses form the biggest diagnostic entity with 71 patients (27.6\%) followed by Depression in 39 patients (15.2\%), Chronic headache in 33 (12.8\%), Alcohol Dependence Syndrome in 27 (10.5\%), Anxiety disorders in 25 (9.7\%) and Dementia in 23 (8.9\%) elderly patients. We also recorded 11 patients (4.3\%) with symptoms of Mania. 'Psychosis' and 'Depression', were more represented amongst female elderly while 'Alcohol dependence' and 'Mania' and were more frequently prevailed among male elderly patient population.

Conclusion: Present study is expected to add some more light on this sub-specialty in Psychiatry and hope to induce more interest among young researchers to carry our further research among geriatric psychiatric patients in Nepal.

Keywords: Geriatric Psychiatry, OPD Study, Nepal

INTRODUCTION
According to United Nations Population Fund (UNFPA) report one out of every 10 person is 
now 60 years or older. As per global trend, Nepal is also witnessing a surge in percentage of population in elderly age group, with gradual rise in life expectancy rate. Life expectancy of Nepalese population has changed from 50 years in 1981 to 60 years by the beginning of current century.

Nepalese population is growing at a rate of $1.35 \%$. Total population of Nepal, as of 2011 census, is 264.9 million (male: 128.4 million, female: 136.4 million) 1 . Elderly population of sixty years and more form $8.14 \%$ of the current total population, as compared to. $6.5 \%$ of total population that was reported during 2001 census. As the population of older people in Nepal is steadily growing, mental health conditions are becoming an important cause of morbidity and premature mortality in this age group.

Various studies have been designed in the past to understand demographic and clinical profiles of elderly psychiatric patients. Some of these studies are Epidemiological field surveys ${ }^{2-5}$, hospital based outpatient studies $^{6-9}$ as well as inpatient studies ${ }^{10-12}$. In the present decade there is resurgence of geropsychiatric study reports from Nepal ${ }^{13-15}$.

Ours is a humble addition to the existing literature on geriatric psychiatric research in Nepal. Aim was to study the demographic and clinical profiles of geriatric outpatients, in the age range of 60 years or more, in our neuropsychiatry OPD and to study the pattern of neuropsychiatric illnesses in these patients.

\section{MATERIAL AND METHOD}

This study was conducted at the Department of Psychiatry, Universal College of Medical Sciences-Teaching Hospital (UCMS-TH), Bhairahawa, Nepal. All the elderly outpatients, in the age range of 60 years and above, from January 2012 to December 2012 (One year) were taken up for the present study. This is a retrospective study by chart review.

We have one Professor, one associate professor and two assistant professors working in the department. At least one faculty member is always available in the OPD on daily basis. We also have two PG residents in each year, thus totaling 6 residents available in the department for routine OPD, inpatient and emergency duties. At least two residents are available in every OPD. All new cases are worked-up by the post-graduate residents in psychiatry first, diagnoses are made according to ICD-10 and discussed with the consultant in-charge of the OPD before noting down the final diagnoses.

We screened through our 'OPD case registrar' of the department. OPD Register in our hospital maintains following demographic and clinical data of all the cases registered daily in the OPD. These are age and sex of the patients and their brief addresses. A note of the final diagnoses were also kept in the OPD register. Caste, region, district and religion of the patients are derived from patients name and addresses noted in the register. These socio-demographic and clinical data of all those patients in the age of 60 years and above were noted in a data sheet specially designed for the present study. Descriptive analysis of these data were undertaken by using simple frequency distribution and t-test and $\mathrm{x}^{2}$-test was used asand-when indicated.

\section{RESULT}

During the one year study period a total number of 13200 patients were registered in our psychiatry OPD. Amongst them number of new cases registered were 3711 (28.1\%). Out of these 3711 new patients $257(6.9 \%)$ were in the geriatric age group ( $\geq 60$ years age).

Table no. 1: Socio-demographic distribution $\underline{(\mathrm{N}=257)}$

\begin{tabular}{|c|l|l|}
\hline Variable & $\mathrm{n}$ & $\%$ \\
\hline 1. Age group: & & \\
60-64 yrs. & 101 & 39.3 \\
65-69 yrs & 62 & 24.1 \\
$70-74$ yrs & 40 & 15.6 \\
$\geq 75$ yrs & 54 & 21.00 \\
\hline 2. Sex: & & \\
Male & 140 & 54.5 \\
Female & 117 & 45.5 \\
\hline 3. Region: & & \\
Tarai & 181 & 70.4 \\
Mountain & 76 & 29.6 \\
\hline
\end{tabular}




\begin{tabular}{|c|l|l|}
\hline 4. Caste & & \\
Brahmin & 83 & 32.3 \\
Chettri & 23 & 8.9 \\
Tharu & 22 & 8.6 \\
Others & 129 & 50.2 \\
\hline 5. Religion & & \\
Hindu & 211 & 82.1 \\
Muslim & 15 & 5.8 \\
Buddhist & 30 & 11.7 \\
Others & 1 & 0.4 \\
\hline 6. District & & \\
Rupendehi & 100 & 38.9 \\
Kapilbastu & 40 & 15.6 \\
Nawalparasi & 30 & 11.7 \\
Palpa & 17 & 6.6 \\
Gulmi & 24 & 9.3 \\
Argahakachi & 15 & 5.8 \\
others & 31 & 12.1 \\
\hline
\end{tabular}

Table no. 1 revealed that almost $40 \%$ of the patients were young old (age range 60-64 years) where as $21 \%$ patients were aged 75 years or more! Male to female distribution was about 55 to 45 percent. Representation from Terai region was approximately $70 \%$. As per demographic distribution of Nepal our patient population also dominated by Hindu religion followed by Buddhists and Muslims. Majority patients were from Terai districts of Rupandehi, Kapilvastu and Nawalparasi.

Table no. 2: Diagnostic distribution of patients (N=257)

\begin{tabular}{|l|l|l|}
\hline Diagnosis & $\mathrm{n}$ & $\%$ \\
\hline Psychosis & 71 & 27.6 \\
\hline BPAD-Mania & 11 & 4.3 \\
\hline Depression & 39 & 15.2 \\
\hline ADS & 27 & 10.5 \\
\hline Dementia & 23 & 8.9 \\
\hline Chronic headache & 33 & 12.8 \\
\hline Anxiety disorders & 25 & 9.7 \\
\hline
\end{tabular}

\begin{tabular}{|l|l|l|}
\hline Others & 28 & 10.9 \\
\hline
\end{tabular}

ADS= Alcohol Dependence Syndrome

Table no 2 showed the diagnostic distribution of elderly patient population who attended our OPD over a period of one year. Psychoses form the biggest diagnostic entity with 71 patients $(27.6 \%)$ followed by Depression in 39 patients (15.2\%), Chronic headache in 33 (12.8\%), Alcohol Dependence Syndrome in $27(10.5 \%)$, Anxiety disorders in $25(9.7 \%)$ and Dementia in $23(8.9 \%)$ elderly patients. We also recorded 11 patients $(4.3 \%)$ presented with symptoms of Mania. Primary insomnia was recorded in 6 patients. Seizure disorder was diagnosed in 5 patients and impotency and other sex related disorders in 5 patients. No diagnosis was noted/recorded in rest 12 cases.

Table no. 3: Diagnosis and sex compared

\begin{tabular}{|l|l|l|}
\hline \multirow{2}{*}{ Diagnosis } & \multicolumn{2}{c|}{ Sex } \\
\cline { 2 - 3 } & Male & Female \\
\hline Psychosis & 32 & 39 \\
\hline BPAD-Mania & 9 & 2 \\
\hline Depression & 18 & 21 \\
\hline ADS & 25 & 2 \\
\hline Dementia & 10 & 13 \\
\hline Chronic headache & 20 & 13 \\
\hline Anxiety disorders & 11 & 14 \\
\hline Others & 15 & 13 \\
\hline
\end{tabular}

When we tried to analyze the influence sex on clinical diagnosis, we found psychosis, depression, dementia and Anxiety disorders were more represented amongst female elderly while Alcohol dependence, Mania and Chronic headache were more frequently prevailed among male elderly patient population.

We wanted to see whether the region the patient belonged to (Terai vs. Mountain region) had any significance bearing to the illness he or she was suffering from, we did not get any. Similarly 
caste or religion of the patient did not have any significant bearing on the diagnostic category.

\section{DISCUSSION:}

\section{PREVALENCE OF GERO-PSYCHIATRIC PATIENTS}

In our study out of 3711 new cases registered over a period of one year, 6.9\% (257) patients belonged to geriatric age group (aged 60 years or more).

Regmi et al. reported $3.2 \%$ of their psychiatric outpatient attendance, over a period of one year, was aged 60 years or more ${ }^{16}$. In another study of socio-demographic and diagnostic profile of patients attending the psychiatric out-patient department of a medical college set-up, $11.1 \%$ were found to be in the age range of 60 years and above ${ }^{15}$.

In a retrospective study of chart review of three years data on the morbidity pattern of psychiatric disorders in patients seeking treatment in Psychiatric OPD of a tertiary care hospital reported $7.6 \%$ of their OPD patient population were 60 years or older ${ }^{13}$. New patients attending Psychiatry OPD of Fewa City Hospital and Research Centre over a period of six months were included in a separate study by Khatri et al. ${ }^{14}$ Out of 887 patients $76(8.5 \%)$ patients were found to be in the age range of 60 years or more.

Hospital outpatient based studies from India and abroad usually reported similar percentage of attendance from geriatric patient population, percentage varying between $4-7 \% 8,9,17$.

\section{AGE \& SEX DISTRIBUTION}

More than sixty percent of our patient population were in the age range of 60-69 years old. Majority of gero-psychiatric patients, reported by different group of researchers in Nepal, are in the same age range.

Male patients contributed $54.5 \%$ (140) and females $45.5 \%$ (117) of our study population. Khatri et al., reported a male to female ratio of 3:1 in their patient population ${ }^{14}$. Koirala et al., reported $42.3 \%$ and Shakya et al., reported $46 \%$ of their study population were male ${ }^{6,7}$. This is in accordance with that reported by others in the hospital based outpatient studies $8,9,18,19$.

Largest diagnostic group amongst both male and female patients were psychosis. Alcohol dependence was more frequently prevailed among male elderly patient population and Depression was more represented amongst female elderly patients.

\section{DIAGNOSTIC BREAK-UP OF ELDERLY PSYCHIATRIC OUT-PATIENTS \\ Table no. 4: comparison between outpatient data of ours with other published data from Nepal}

Our study revealed a higher percentage $(26.4 \%)$ of geriatric patient population suffer from psychotic illness, followed by mood disorder, chronic headache, dementia, Alcohol dependence syndrome and anxiety disorder patients.

Diagnostic profile among senior citizens attending the psychiatric outpatient department of a tertiary health care facility in Nepal was reported by Koirala and his team in the year $2000^{6}$. They reported $30.7 \%$ of their geriatric psychiatric patient population had mood disorder, $28 \%$ had organic brain disorders and 9.3\% was diagnosed as tension headache cases.

In a 'psychiatric morbidities of elderly psychiatry out-patients' survey, at a tertiary-care hospital, Sakya reported major psychiatric diagnoses were mood (affective) disorder (46\%), anxiety disorders (22\%), substance use disorders (19\%), organic and symptomatic psychiatric disorders (12\%) and somatoform disorders $(10 \%)^{7}$.

In another psychiatric morbidity study Thapa et al., reported Mood disorder in 32.2\%, Dementia in $12.5 \%$, Anxiety disorder in $23.3 \%$, ADS in $11.3 \%$ and Psychosis in $13.3 \%$ of their in elderly patients attending psychiatry $\mathrm{OPD}^{20}$.

Thus, we see different centres from different parts of Nepal have different diagnostic distribution pattern of their elderly psychiatric out-patients. Whereas, late onset psychoses outnumbered other diagnoses at Bhairahawa centre; centres at Kathmandu and Dharan reported Mood disorder as their most frequent diagnosis. Percentage of Chronic headache in elderly patients at our centre was much higher that reported by Koirala et al from Kathmandu. Shakya et al and Thapa et al did not mention anything about headache in their elderly patients, probably, they did not considered headache clinic statistics in their study. 


\section{MOOD DISORDER}

Our study showed that $19.5 \%$ of our geriatric patients had a diagnosis of mood disorder (Depression $=15.2 \%$ and Mania $=4.3 \%$ ). Mood (affective) disorder is usually the largest diagnostic rubric, in most reported studies on gero-psychiatric patient population, in Nepal, India and other countries $7,18,21$.

Sakya reported $46 \%$ of his outpatient geriatric psychiatric patients were having mood (affective) disorder ${ }^{7}$. Koirala et al., reported that $30.7 \%$ of their geriatric out-patients could be diagnosed as mood disorder ${ }^{6}$. Ritchie et al., reported a lifetime prevalence of $26.5 \%$ of major depression in their geriatric psychiatric patients $^{21}$. But Draper reported a very high 53\% depressive disorder (43\% major depression plus $10 \%$ dysthymia) in his series of inpatient geropsychiatric patients ${ }^{12}$.

Though our figure is lower than above published studies, our figures are at par with few other studies reported from India and abroad $5,9,22,23$. Martha et al., found that $13.5 \%$ of newly admitted elderly home care patients suffered from major depression ${ }^{23}$.

Prevalence of Mania in our geropsychiatric patient population was $4.3 \%$. Reported prevalence of mania amongst geriatric psychiatric patients is found to be low $(1-2 \%)$ in both inpatient as well as community prevalence studies from western countries ${ }^{12,21}$. Most Indian studies also did not elaborate much on the prevalence of mania in this age group, although one study reported $7.1 \%$ mania in their geropsychiatric patient population ${ }^{19}$. Comparatively, an inpatient study from Bhairahawa reported a much higher (15.9\%) attendance of mania amongst their geriatric psychiatric patients ${ }^{11}$.

\section{PSYCHOSIS}

Our data on OPD attendance of geriatric patients showed a higher percentage $(26.4 \%)$ of patients with a diagnosis of psychosis. But, Koirala et al reported only $1.3 \%$ of their geriatric patients had a diagnosis of psychosis while Shakya reported the same rate as $6 \% 6,7$. While one epidemiologic survey found this rate to be $22.2 \%{ }^{5}$, rates from various hospital-OPD based studies from India vary from $17 \%$ to $33 \% 9,18,19$.
Thus late onset psychosis, which was hitherto comparatively unknown diagnostic entity in Nepal in the past, is gradually making its appearance in newer studies. This figure probably indicate a better access of mental health facility to common people and better awareness of common people to mental illness and acceptability of modern treatment in relation to mental illness by the present day society, at large.

\section{ORGANIC MENTAL DISORDER}

Amongst elderly patients who attended our OPD during the schedule one year period $8.9 \%$ fulfilled a clinical diagnosis of Dementia. Sakya reported $12 \%$ of their patients had organic and symptomatic psychiatric disorders ${ }^{7}$. But, Koirala et al., reported a very high rate $(28 \%)$ of organic brain illnesses in their geriatric psychiatric outpatients 6 .

These rates are a bit higher than that of hospital outpatient based study reports from India, which varies from 6 to 9 percent $5,9,19$.

\section{ANXIETY DISORDER}

Current study revealed a lower percentage $(9.7 \%)$ of our geropsychiatric out-patients presented with symptoms of anxiety disorders. Koirala et al., reported $8 \%$ of their geriatric outpatients had a diagnosis of Anxiety disorder6. But, Sakya reported a high 22\% prevalence of anxiety disorders in their geriatric psychiatric out-patient population ${ }^{7}$. Anxiety in geriatric outpatient population, that had been reported from in India varies from $7 \%$ to $16 \% 9$, 18,19 .

But, prevalence of anxiety disorder is reported to be much higher in community surveys. In a community survey in the state of Uttar Pradesh in India, 53.9\% geropsychiatric patients were reported to be suffering from Neurotic disorder according to ICD-95. Ritchie et al also reported lifetime prevalence of anxiety disorder was 30\% amongst French elderly population ${ }^{21}$.

Amongst various diagnostic rubrics in psychiatry, anxiety disorders are probably treated mostly at OPD level as they need less inpatient care. Nevertheless, it is a true fact that Neurotic, stress related and somatoform disorders in the elderly have received lesser 
attention than mood disorders and organic mental disorders esp., dementia ${ }^{18}$.

\section{ALCOHOL DEPENDENCE SYNDROME (ADS)}

We found $10.5 \%$ of our geropsychiatric outpatient population were having a diagnosis of Alcohol Dependence Syndrome (ADS). Our study finding is in sharp contrast to most outpatient studies reported from India and Nepal, which reported an alcohol dependence rate ranging from $1 \%$ to $5 \% 6,14,18,19$. Only one study reported much higher percentage $(33 \%)$ of ADS amongst geropsychiatric outpatients was that reported by Sakya in 2011 .

Khattri et al., did a study on the pattern of alcohol dependence syndrome among older adults attending psychiatry OPD of Fewa City Hospital and Research Centre, Pokhara in western region of Nepal. A total of 80 elderly patients aged 65 years and above were taken up for the study. They reported five percent of their samples could be diagnosed as alcohol dependence syndrome $^{14}$. Koirala et al., found that only 1.3 percent of the elderly patients were using alcohol at the dependent level ${ }^{6}$.

We found that out of total $27(10.5 \%)$ alcohol dependent elderly persons most (25) were male and rest 2 were female patients. Elderly male gender is established as an important risk factor for drinking related problems ${ }^{24}$. In USA alcohol and substance abuse have been reported to be the third leading health problem among those aged more than 55 years, constituting $10 \%$ of all cases treated by geriatric mental health facilities ${ }^{25,26}$.

\section{OUTPATIENT vs. INPATIENT DATA COMPARED:}

Table no. 5: Geriatric Inpatient and outpatient data compared at our institute (in percentage).

\begin{tabular}{|l|l|l|}
\hline \multirow{2}{*}{ Diagnosis } & \multicolumn{2}{|c|}{$\begin{array}{l}\text { UCMS- Department of } \\
\text { psychiatry }\end{array}$} \\
\cline { 2 - 3 } & $\begin{array}{l}\text { Outpatient data } \\
(\mathrm{N}=257) \\
\text { (Present study) } \\
\%\end{array}$ & $\begin{array}{l}\text { Inpatient data } \\
(\mathrm{N}=138) \\
\text { Aich et al. (2012) } \\
\%\end{array}$ \\
\hline Psychosis & 27.6 & 20.3 \\
\hline Mania & 4.3 & 15.9 \\
\hline Depression & 15.2 & 23.2 \\
\hline ADS & 10.5 & 6.5 \\
\hline Dementia & 8.9 & 12.4 \\
\hline Anxiety & 9.7 & \\
\hline disorders & 12.8 & 6.1 \\
\hline Headache & & \\
\hline
\end{tabular}

Though these two studies are carried out at different point of time, we can have a rough idea on the pattern of presentation of geriatric psychiatric patients at out-patient and in-patient set-up. It has been revealed that headache patients are exclusively treated in out-patient setting only. Most Manic patients needed inpatient treatment. Higher percentage of patients with diagnosis of Depression, ADS and Dementia also needed inpatient treatment.

Aich et al., in their inpatient study reported Alcohol dependence being the largest diagnostic group among geriatric male patients and depression formed the largest diagnosis category among geriatric female patients ${ }^{11}$. But, current outpatient study revealed Psychosis to be the largest diagnostic group in both male and female geriatric patients, followed by ADS in male and Depression in female patients (Table no 3). Thus, it may be concluded that successful treatment of many psychosis patients is possible and is being offered at OPD level only. 


\section{CONCLUSION:}

We tried to analyze the demographic and clinical presentations in our geropsychiatric patients, who attended to our OPD over a period of one year. We found a high attendance of late onset psychosis amongst our geropsychiatric out-patients population. Besides, Mood disorders (depression), Alcohol dependence syndrome and chronic headache form the bulk of our patient population. Though mood disorders (mania) form a small $4.3 \%$ of our OPD patient population, it is apparent that most of them got admitted and received inpatient treatment. ADS patients also mostly received inpatient treatment after consultation at OPD. Headache patients are exclusively treated at outpatient level only.

Geriatric psychiatry research in Nepal took its first foot forward following publication of an article by Nabaraj Koirala and his team in the year 2000 titled "Geriatric Psychiatry: Sociodemographic characteristics and diagnostic profile among senior citizens attending the psychiatric outpatient department of a tertiary health care facility in Nepal"8. But, geriatric psychiatry research in Nepal is still, probably, in its early stages of development. It is only of late that we have few more published studies and reviews on geropsychiatric patients in Nepal. ${ }^{20,27}$ Present study is expected to add some more light on this sub-specialty in Psychiatry and hope to induce more interest among young researchers to carry our further research among geriatric psychiatric patients in Nepal.

\section{REFERENCES:}

1. National population and housing census 2011: national report. Downloaded from: http://unstats.un.org/unsd/demographic/ sources/census/2010_PHC/Nepal/NepalCensus-2011-Vol1.pdf.

2. Subedi S, Tausig M, Subedi J, et al. Mental Illness and Disability among Elders in Developing Countries: The Case of Nepal. J Aging Health 2004; 16 (1): 71-87

3. Khattri JB, Poudel BM, Thapa P et al. An Epidemiological Study of Psychiatric Cases in a Rural Community of Nepal. Nepal J Medical Sciences 2013; 2(1):52-6

4. Nandi DN, Ajmani S, Ganguli $\mathrm{H}$ et al. Psychiatric disorders in a rural community in West Bengal: An epidemiological study. Indian J Psychiatry 1975; 17: 87-90.
5. Tiwari SC, Srivastava S. Geropsychiatric morbidity in rural Uttar Pradesh. Indian J Psychiatry 1998; 40: 266-273.

6. Koirala NR, Nepal MK, Sinha UK, et al. Geriatric Psychiatry: Socio-demographic characteristics and diagnostic profile among senior citizens attending the psychiatric outpatient department of a tertiary health care facility in Nepal. J Institute of Medicine 2000; 22:221-226.

7. Shakya DR. Psychiatric morbidities of elderly psychiatry out-patients in a tertiarycare hospital. J College Med Sciences Nepal 2011; 7(4); 1-8.

8. Prasad KMR, Sreenivas KN, Ashok MV et al. Psychogeriatric patients - A sociodemographic and clinical profile. Indian J Psychiatry 1996; 38(3); 178-181.

9. Pereira YDS, Estibeiro A, Dhume $\mathrm{R}$ et al. Geriatric patients attending tertiary care psychiatric hospital. Indian J Psychiatry 2002; 44(4): 326-331.

10. Kumar A, Sharma, SR, Timalsina $S$ et al. High Prevalence of Depression and Anxiety Symptoms among Hospitalized Geriatric Medical Inpatients of Nepal: A Study from a Tertiary Level Hospital of Nepal. UTMJ 2011; 88 (1), 32-35.

11. Aich TK, Dhungana M, Muthuswamy R. Pattern of neuropsychiatric illnesses in older age group population: An inpatient study report from Nepal. Indian J Psychiatry 2012; 54(1):23-31.

12. Draper B. The elderly admitted to a general hospital psychiatry ward. Aust N Z J psychiatry 1994; 28: 288-297.

13. Shrestha MR, Pradhan S, Sharma S. Morbidity Pattern of Psychiatric Disorders in Patient Seeking Treatment in Psychiatric OPD of Private Tertiary Care Hospital. PMJN 2011; 11(1):28-33.

14. Khattri JB, Godar ST, Thapa P, et al. Sociodemographic characteristics and diagnostic profile of patients attending psychiatric OPD of a private hospital in western region of Nepal. Nepal J Medical Sciences. 2012; 1(1): 15-18.

15. Koirala NR, Yadav R, Das AK, et al. A study of socio-demographic and diagnostic profile of patients attending the psychiatric outpatient department of Nobel medical college, Biratnagar. J Nobel Med College 2012; 1(2):45-49.

16. Regmi SK, Khalid A, Nepal MK et al. A study of socio-demographic characteristics and diagnostic profile in psychiatric 
outpatients of TUTH. Nepalese J Psychiatry 1999; 1(1): 26-33.

17. Bhogale GS, Sudarshan CY. Geriatric patients attending a general hospital psychiatry clinic. Indian J Psychiatry 1993; 35(4): 203-205.

18. Singh GP, Chavan BS, Arun P et al. Geriatric outpatients with psychiatric illnesses in a teaching hospital setting - A retrospective study. Indian J Psychiatry 2004; 46(2): $14-$ 143. (1

19. Tiple $P$, Sharma SN, Srivastava AS. Psychiatric morbidity in geriatric people. Indian J Psychiatry 2006; 48: 88-94.

20. Thapa P, Chakraborty PK, Khattri JB, Ramesh K, Sharma B. Psychiatric morbidity in elderly patients attending OPD of tertiary care centre in western region of Nepal. Industrial Psychiatry J 2014; 23(2): 101-4.

21. Ritchie K, Artero A, Beluche I, et al. Prevalence of DSM-IV psychiatric disorder in the French elderly population. $\mathrm{Br} \mathrm{J}$ Psychiatry 2004; 184: 147-152

22. Ramchandran V, Sarda Menon M, Ramamurthy B. Psychiatric disorders in subjects aged over fifty. Indian J Psychiatry 1979; 22: 193-198.

23. Martha L, Bruce Gail J, Mc Avay, et al. Major depression in elderly home health care patients. Am J Psychiatry 2002; 159: 1367-74.

24. O'Connell $\mathrm{H}$, Chin AV, Cunningham C, et al. Alcohol use problems in elderly people redefining an age-old problem in old age. BMJ 2003; 327: 664-667.

25. Reifler B, Raskind M, Kethley A. Psychiatric Diagnoses among geriatric patients seen in an outreach program. J Am Geriatr Soc 1982; 530-533.

26. Zimberg S. Alcohol abuse among the elderly. In: Carstensen LL \& Edelstein BA, ed. Handbook of Clinical Gerontology, New York: Pergamon Press, 1987; 57-65.

27. Aich TK, Lamichane N, Koirala NR, Ranjan S. Geriatric psychiatry research in Nepal: an overview and current status. In Souvenair: 5th National Conference of the Psychiatrists' Association of Nepal, 2013; 58-67. 